\title{
O Brasil na América Latina: diante de uma ideia de literatura mundial
}

\author{
Brazil in Latin America: in front of an idea of world literature
}

Brasil en América Latina: ante una idea de literatura mundial

leda Magri

\section{Resumo}

Este artigo buscará pensar de que maneira a literatura brasileira aparece na corrida para fazer parte de uma literatura-mundo. A partir da imposição mesma de uma economia pensada numa relação de mundo presente no vocábulo globalização, a proposição de Goethe de uma literatura mundial passa a ser o ponto de partida para o estudo dessa inserção. Observou-se que reservar um lugar periférico dentro do pecúlio comum do mundo às literaturas da América Latina não é suficiente para incluí-la no discurso do "mundial" e muito menos para efetivar o que Spivak chama de "uma competição limpa". Ainda mais especificamente, interessa pensar o caso do Brasil dentro da América Latina, sua posição ainda mais periférica em relação à inserção na literatura-mundo, e que tem, no entanto, outras ressonâncias a partir dos estudos de Franco Moretti e das novas publicações de Machado de Assis nos Estados Unidos, que deram visibilidade à crítica brasileira que aborda essas questões.

Palavras-chave: literatura mundial, literatura brasileira, América Latina.

\section{Abstract}

This article analyzes where Brazilian literature stands in the race to be part of world literature. From the very imposition of an economy conceived of in a global relationship, manifest in the word globalization, Goethe's proposition of a world literature is the starting point for the study of Brazilian literature's standing within this sphere. It has been noted that to allot a peripheral share of the world's common nest egg to Latin American literatures is not enough to include it in the "world" forum, let alone to implement what Spivak calls "a clean competition." More specifically, it is important to think about the case of Brazil within Latin America, whose position is thus doubly peripheral within the scope of world literature. Nevertheless, Brazilian literature has achieved other resonances, from the studies of Franco Moretti to the new publications of Machado de Assis in the United States, which gives visibility to the Brazilian criticism addressing these issues.

Keywords: world literature, Brazilian literature, Latin America.

\section{Resumen}

Este artículo buscará pensar de qué manera la literatura brasileña aparece en la pugna por formar parte de una literatura-mundo. A partir de la imposición misma de una economía pensada en la relación de mundo presente en el vocablo globalización, la proposición de Goethe de una literatura mundial pasa a ser el punto de partida para el estudio de esa inserción. Se observa que reservar un espacio periférico dentro del peculio común del mundo a las literaturas de América Latina no es suficiente para incluirla en el discurso de lo "mundial" y mucho menos para llevar a cabo lo que Spivak llama "una competición limpia". Más especificamente, es de nuestro interés pensar el caso de Brasil dentro de América Latina, su posición aún más periférica en relación a la inserción en la literatura-mundo, y que tiene, sin embargo, otras resonancias a partir de los estudios de Franco Moretti y de las nuevas publicaciones de Machado de Assis en los Estados Unidos, que dieron visibilidad a la crítica brasileña que aborda estas cuestiones.

Palabras clave: literatura mundial, literatura brasileña, América Latina.

\footnotetext{
" Doutora em literatura brasileira e professora da Universidade Estadual do Rio de Janeiro (UERJ). (Dorcid.org/0000-0002-48093811. E-mail: iedamagri@yahoo.com.br
} 


\section{A literatura mundial e a América Latina}

A ideia de um estudo da literatura além das fronteiras nacionais, uma espacialização do olhar sobre um campo amplo, um campo capaz de visualizar a teia mundial do universo literário, foi proposta, como é sabido, ainda por Goethe em uma série de textos marginais, como prólogos, artigos em revistas etc. ${ }^{1}$ Para ele, a literatura mundial se compõe de um conjunto de práticas e valores que, transcendendo as fronteiras nacionais, permite conceber o exercício da literatura como uma espécie de ágora transnacional. Também por Marx e Engels no Manifesto Comunista: "As obras intelectuais de uma nação tornam-se propriedade comum de todas. A estreiteza e o exclusivismo nacionais tornam-se dia a dia mais impossíveis, e da multiplicidade das literaturas nacionais e locais nasce uma literatura universal" (apud Campos, 2000, p. 287). A partir da imposição mesma de uma economia pensada numa relação de mundo, presente hoje no termo globalização, essas duas propostas, a de Goethe e a de Marx e Engels, passam a ser os pontos de partida para o estudo do que acontece com a literatura num mundo cada vez mais globalizado. A premissa de uma literatura mundo iria deslocar consideravelmente o modo de conceber os estudos da literatura, especialmente no âmbito da literatura comparada.

Franco Moretti, para partir de um texto que gerou muitas polêmicas, em Conjectures on world literature, publicado em 2000, propõe a transformação do estudo da literatura mundial de um ideal a um método, com o que ele chama de "distant reading" em oposição ao "close reading" anglo-saxão e de relevância nas escolas críticas herdeiras do estruturalismo. Assim, em vez do close reading, Moretti propõe uma espécie de leitura à distância para dar conta da complexidade da literatura mundial, ficando a encargo de críticos nacionais ou regionais a tarefa de eleger os textos de maior vulto, realizando deles uma leitura textual, enquanto ao crítico da literatura mundial caberia buscar padrões comuns entre essas obras representativas das culturas nacionais. Dessa maneira, crê Moretti, seria possível descentralizar a visão da literatura centrada no mundo euro-norte-americano. Ele coloca em prática essa proposição em seu livro Graphs, maps, trees (gráficos, mapas, árvores), publicado fora da Inglaterra (assim como no Brasil) com o título A literatura vista de longe, e sustenta uma teoria comparativa não baseada na geografia, necessariamente nas literaturas nacionais, entre a literatura de um país e outro e suas semelhanças e diversidades, mas na evolução das formas literárias no tempo e no espaço. Ou seja, partindo-se de um corpus literário não necessariamente nacional, mas geograficamente localizado, migra o estudo para uma questão conceitual que perpassa todas as literaturas, buscando um padrão. Assim, construindo gráficos, mapas e árvores, em seu estudo sobre a evolução da forma romanesca, Moretti mostra que os gêneros literários não sobreviveriam sem a variação cultural. O romance de formação, por exemplo, que nasceu na Europa depois da Revolução Francesa para dar conta de uma necessidade social, a "mediação dos conflitos que surgem na busca por liberdade e igualdade" (Moretti, 2005, p. 99) ressurge nos Estados Unidos, de modo completamente diferente, com Salinger e seu $O$ apanhador no campo de centeio, transplantando uma forma que havia exaurido sua função social na Europa. Dessa maneira, Moretti sugere o estudo da evolução da forma nas diferentes culturas do Globo, como uma possível solução para o estudo das literaturas sem cair nas armadilhas da relação de dependência entre culturas, evidenciando o caráter de complementariedade que há entre estas.

Moretti parte de um insight de Jameson. Provada a validade do insight, torna-se "lei de Jameson": "Em culturas que integram a periferia do sistema literário (quase todas, menos França e Inglaterra e Alemanha) o romance moderno desponta não como desenvolvimento autônomo, mas como uma conciliação entre uma influência formal ocidental (francesa ou inglesa) e matéria/conteúdo locais". Assim, por exemplo, prova-se como Aluísio Azevedo escreveu $O$ cortiço com a forma d'A comédia humana de Balzac e o conteúdo do Brasil entre a

\footnotetext{
${ }^{1}$ Eloá Heise (2007, p. 37), no artigo "Weltliteratur, um conceito transcultural", faz um apanhado das proposições de Goethe em torno do conceito, partindo das conversações com Eckermann: "A primeira manifestação de Goethe, na qual é mencionado o termo Weltliteratur, é de 1827, data em que Goethe proclama, em uma conversa com Eckermann, ter chegado a época de uma literatura universal. A partir de então, o conceito aparece, de forma recorrente, em conversas, cartas, resenhas e ensaios da última fase do grande clássico alemão, apontando para a relevância que tal ideia adquire no pensamento do velho Goethe".
} 
cultura do português colonizador e uma malandragem baiana e carioca. Moretti muda um pouco sua lei de Jameson e acrescenta um ponto: em vez de conciliação entre forma estrangeira e material local simplesmente, ele vê uma conciliação entre uma forma estrangeira (o enredo) e o material local (as personagens locais) e uma voz narrativa também local.

O método de Moretti segue o modelo das ciências: define-se uma unidade de análise (o romance; o estilo indireto livre); seguem-se suas metamorfoses/variações numa variedade de ambientes. A descoberta: a literatura mundial é um sistema de variações (todas as literaturas se inter-relacionam, mas a pressão do centro para torná-la uniforme não pode apagar a diferença). Por isso, a literatura seria "una e desigual". Logo, para ele, o estudo da literatura mundial é um estudo da luta pela hegemonia simbólica ao redor do mundo. O empenho de Moretti está centrado na busca de um método para dar conta verdadeiramente do estudo da literatura produzida mundialmente. De todas as maneiras, se - principalmente com seus conceitos de distant reading e de mapa, que buscam dar conta das articulações do espaço geográfico mundial - Moretti consegue descrever o sistema literário mundial em suas relações de forças, o problema do estabelecimento de quais obras são relevantes em âmbito nacional e que poderiam ascender ao terreno de uma literatura transnacional permanece o mesmo. E, ao delegar aos críticos nacionais a tarefa de ler a sua literatura e escolher aquela que seria representativa, torna $o$ crítico mundial um crítico de segunda mão. Sem falar na questão que se coloca quanto a quais críticos nacionais ele vai dar crédito. Umas são as obras lidas por Roberto Schwarz, seu interlocutor brasileiro, outras as lidas por Silviano Santiago. Outro problema é que Moretti só estuda o romance, mas fala dele como se fosse toda a literatura.

Pascale Casanova, em seu livro A república mundial das letras, toma de Bourdieu uma concepção espacial de literatura que descreve o campo literário como um conjunto de relações de poder em um mapa geocultural cuja lógica opera com autonomia relativa em relação ao mapa geopolítico. Dessa forma, para a autora, a base do sistema literário não está radicada em estéticas específicas, mas em sua legitimação e posterior reprodução em um sistema discursivo concreto que se mostra em traduções, edições etc. O sistema literário poderia ser definido como negociação que se dá entre o centro legitimador - Paris - e as diversas nações periféricas, ainda que esse centro, atualmente, migre de uma nação a outra na disputa pela hegemonia francesa, tendo em vista os modos de legitimação: prêmios, traduções para o maior número possível de línguas, acolhimento entre os críticos que têm influência e conseguem dar prestígio à obra. É fácil deduzir daí que o escritor desses países periféricos enfrenta uma luta pela legitimação em seu país em busca do direito de "existir", no sistema literário mundial, ou seja, transnacional. "A configuração do espaço literário contemporâneo é difícil de esboçar. Talvez estejamos hoje em uma fase de transição, passando de um universo dominado por Paris a um mundo policêntrico e pluralista, onde Londres e Nova York principalmente, mas também, em menor medida, Roma, Barcelona, Frankfurt... disputam a hegemonia literária de Paris" (Casanova, 2002, p. 205).

Para Casanova, os contornos e fronteiras do espaço literário mundial nunca foram traçados ou descritos e encarnam-se nos próprios escritores. Eles são e fazem a história literária a partir de suas lutas específicas que garantirão sua existência literária mundial, e seu acesso muitas vezes é, portanto, quase heroico. Para dar a compreender essa proposição, ela parte do texto de Henry James, $O$ motivo no tapete. Tal como um grande tapete cujo desenho só pode ser visto inteiramente se nos afastarmos de maneira apropriada, também as obras literárias exigiriam certo distanciamento do crítico que lhe permitiria "comparar as formas recorrentes, as semelhanças e as dessemelhanças com outras formas" (Casanova, 2002, p. 17), o que faz Moretti. O exercício de leitura da produção de uma obra exigiria a leitura de todo o espaço literário de que essa obra faz parte como continuação ou ruptura da tradição a partir de uma ideia de literatura nacional. Assim, "a 'complexidade maravilhosa' da obra misteriosa poderia encontrar seu princípio na totalidade, invisível e contudo oferecida, de todos os textos literários através e contra os quais ela pôde se construir e existir e da qual cada livro publicado no mundo seria um dos elementos" (Casanova, 2002, p. 17).

Diferentemente de Moretti, Casanova pensa o problema da literatura mundial a partir da dessincronização dos diferentes "mundos" mais do que a partir de seus lugares na 
geografia. Para existirem além das fronteiras do espaço nacional e da língua, os escritores empreenderiam revoluções que têm a ver com uma modernidade literária, valor espaçotemporal medido pelo "meridiano de Greenwich literário": sua distância, no tempo, do presente específico da modernidade cujo centro seria Paris. Isso equivale a dizer que as obras participam de tempos diferentes num mesmo espaço, o mundo, o grande tapete. Essa medida de tempo é conceituada a partir de Bourdieu:

Conforme a expressão de Pierre Bourdieu [em Homo academicus] há um "tempo" próprio aos acontecimentos capazes de "marcar época" no universo literário que só pertence a ele e que não é necessariamente "sincrônico" com a medida do tempo histórica (isto é, política) que se impôs como oficial e legítima. O espaço literário institui um presente a partir do qual todas as posiç̃̃es serão medidas, um ponto com relação ao qual se situarão todos os outros pontos. [...] A distância estética é medida igualmente em termos temporais: o meridiano de origem institui o presente, isto é, a modernidade na ordem da criação literária. Assim é possível medir a distância do centro de uma obra ou de um corpus de obras a partir de sua distância temporal dos cânones que definem o presente da literatura no momento preciso da avaliação (Casanova, 2002, p. 116).

Assim, uma obra seria moderna, na medida em que se aproxima do que é moderno em Paris, instituída como o presente literário por figurar no imaginário dos escritores como o centro onde as coisas acontecem, como o lugar da produção da moda, ou como disse Gertrude Stein: "Paris estava onde se encontrava o século XX" (Casanova, 2002, p. 117), o que nos remete também ao conhecido texto de Benjamin nas Passagens: "Paris, capital do século XIX". O lugar por excelência de contestação do presente como ultrapassado, sempre defendendo um presente mais presente.

Reconhecer a influência francesa sobre as diversas literaturas nacionais não é tarefa difícil. Na América Latina, é Borges quem autoriza essa concepção da França como medida de modernidade. E Casanova recolhe a "surpreendente aventura revolucionária" da América Latina, em entrevista de Borges de 1986:

Tive a profunda certeza de que a poesia espanhola, a partir do Século de Ouro [...] entrara em decadência [...]. Tudo tornava-se rígido. [...] Não falemos do século XVIII, nem do século XIX, que foram muito pobres [...]. E, bruscamente, surge Rubén Darío, que a tudo renova! Uma renovação que, após a América, chega à Espanha e inspira grandes poetas como os Machado e Juan Jiménez, para citar apenas três; mas há outros, sem dúvida [...] ele foi precisamente o primeiro dos renovadores. Sob a influência, é claro, de Edgar Allan Poe. Que coisa estranha: Poe é americano, nasce em Boston e morre em Baltimore; mas chega à nossa poesia graças a um francês, Baudelaire, que o traduziu [...]. De modo que, no fundo, essa influência é sobretudo francesa (Casanova, 2002, p. 127).

Mas a aposta de Casanova de Paris como o berço da modernidade literária é um dos pontos que mais gera polêmica em sua obra, tendo em vista o argumento de que, em que pesem as influências, não se poderia negar que uma obra de uma nação periférica pode não só se aproximar da modernidade instituída por Paris, mas fundar uma nova modernidade. É precisamente o que faz Ignacio Sánches-Prado em América latina en la literatura mundial ao afirmar, a partir dos estudos de Beatriz Sarlo sobre Borges, que este não ingressa na modernidade, ele a destrói. Borges é o escritor de maior influência mundial a partir do século XX, capaz de modificar o olhar do europeu sobre a América Latina, e sobre o próprio conceito de literatura, ou seja, é a irrupção da margem no centro.

A canonização mundial de Borges não foi devida ao fato de Borges ter sido construído pelo espaço editorial europeu ou pelas lógicas transatlánticas do mercado literário, mas porque sua estética da margem implicou em uma ruptura profunda dos pressupostos intelectuais da modernidade europeia (Sánches-Prado, 2006, p. 32, tradução nossa).

Apesar de ter anotado que a partir de 1960 a França perde a hegemonia em torno da legitimação da literatura no menor dos capítulos de seu livro, o final da primeira parte, Pascale Casanova orienta todo o seu estudo pela cisão entre "capital" e "província", sendo Paris a capital e o resto do mundo a província. "A defasagem entre a capital e a província", diz ela, "é inseparavelmente temporal e estética: a estética é simplesmente outra maneira de 
denominar o tempo da literatura" (Casanova, 2002, p. 124). É nesse sentido que, sem nunca definir "literariedade" senão como um valor específico ligado ao prestígio de uma língua literária - "capital linguístico-literário" (Casanova, 2002, p. 33); "o poder, o prestígio, o volume de capital linguístico-literário" (Casanova, 2002, p. 37)-, o valor estético-temporal instituidor de modernidade é o próprio pertencer ao que é tido como moderno (leia-se novo, válido, transgressor das normas nacionais) na "capital". Assim,

A única maneira de recusar a norma literária londrina (ou de recusar sua condenação ou sua indiferença) para um irlandês por volta de 1900 (como Joyce), para um americano por volta de 1930, o único meio para um nicaraguense por volta de 1890 (como Rubén Darío) se desviar das normas literárias acadêmicas espanholas, para um iugoslavo por volta de 1970 (como Danilo Kis) recusar as influências das normas impostas por Moscou, para um português (como Antônio Lobo Antunes) por volta de 1995 sair de um espaço nacional coercitivo, é voltar-se para Paris (Casanova, 2002, p. 125).

É justamente nessa não discussão do valor de modernidade que o crítico uruguaio Hugo Achugar irá lançar as bases de sua recusa dos termos de Pascale Casanova para pensar literatura mundial e América Latina, pensando a "impossível universalidade da 'literatura universal'" (Achugar, 2006, p. 206). A questão fundamental para este crítico (e grande parte dos críticos latino-americanos, como Fernandez Retamar e o próprio Sanches-Prado, organizador da coletânea), é a de considerar o "lugar de enunciação" da própria crítica. O lugar de enunciação leva em conta diferentes valores estéticos e diferentes concepções de literatura:

A noção de "campo mundial" que, elaborada a partir de Braudel e Bourdieu, [Casanova] utiliza com engenho para descrever a formação e a fabricação do sistema da literatura mundial surge de um lugar de enunciação que pressupõe um "a priori estético" onde existe o "autenticamente universal" e aquilo que não o é (Achugar, 2006, p. 202).

Desse modo, Achugar instaura a discussão dos valores, do universal e do nacional, chegando a uma síntese perturbadora, cuja crítica pode ser estendida também à ideia presente em todos os debates sobre o tema, a da forma original europeia (em que se somam o universal e o ocidental) e a adaptação copiadora/plagiadora/modificadora periférica:

Uma coisa é descrever a centralidade e universalidade da "nação Vuitton" e desqualificar os habitantes "das nações que pirateiam Vuitton", outra, no entanto, é ignorar que existam universos em que "Vuitton" é um significante vazio e o que tem sentido para tais universos nem sequer é registrado pelo panóptico universalista (Achugar, 2006, p. 206).

No livro organizado por Sánches-Prado concretiza-se de forma muito incômoda a pergunta: como pensar o ingresso no debate mundial a partir dos valores do centro legitimador? E: pensar em termos de uma literatura mundial será mesmo viável? Duas perguntas que não encontram respostas definitivas.

As dificuldades são imensas, muito maiores se pensarmos que a literatura mundial é composta por $1 \%$ do que chamamos de cânone e $99 \%$ da literatura esquecida, como diz Moretti. Mesmo assim, diz ele, uma vida não basta para ler esse $1 \%$ de cada nação e ninguém inventou um novo método para se ler mais livros. Será, no entanto, desejável dar conta do todo tanto quando é desejável sair do aprisionamento de uma leitura circunscrita em termos de nação?

Gayatri Chakravorty Spivak vê, especialmente em Moretti, o problema maior da discussão em torno de uma literatura mundial: "Os outros provêem informações enquanto nós [os americanos] conhecemos o mundo inteiro" (Spivak, 2009, p. 127, tradução nossa). O crítico nacional continua periférico, o crítico mundial é capaz de ler a totalidade. O problema que ela ataca: renunciar à aprendizagem das línguas diferentes (todos precisam aprender o inglês para fazer a crítica mundial; ao crítico inglês ou norte-americano basta o inglês, sua língua). $O$ imperialismo linguístico se soma ao imperialismo econômico. Ela sugere, então, que se considerem as línguas do hemisfério sul como meios culturais ativos mais que como objetos de estudos culturais. O crítico, assim, seria um intérprete, aquele que fala entre duas partes ou aquele que privilegia sempre no estudo da literatura mundial o ponto de vista outro, aquele que provém da margem. "O conhecimento de uma só cultura significa nacionalismo estadunidense 
disfarçado de globalização", diz ela. E, mais: "Uma literatura mundial que seja apenas crítica enciclopédica é necessariamente superficial e insatisfatória" (Spivak, 2009, p. 128).

Numa ideia de literatura mundial mais rasa, a América Latina segue sendo o lugar de produção de casos de estudo, mas não um lugar de enunciação legítimo. De que maneira a pergunta por quem somos e quem é o outro pode recolocar os termos da proposição de uma literatura mundial? Ainda a resposta de Spivak: seria preciso conquistar a competição limpa, dar as mesmas condições a todos os jogadores seria a única maneira de se pensar em termos de sistema-mundo. Isso não parece possível se pensamos a literatura a partir dos modelos econômicos de globalização. Spivak lembra que "as fronteiras se cruzam facilmente a partir dos países metropolitanos, enquanto que tentar entrar a partir dos países periféricos é encontrar limitações burocráticas que, somadas às policiais, tornam o ingresso ainda mais difícil". E, de modo conclusivo: "Pese a que os efeitos da globalização se deixam sentir em todo o mundo, pese a haver antenas parabólicas no Nepal, nunca acontece o oposto" (Spivak, 2009, p. 27, tradução nossa).

Spivak defende, em Muerte de una disciplina, no que diz respeito ao estudo das diferentes culturas na renovação metodológica da literatura comparada (questão que une os interesses diversos de Spivak, Moretti e Casanova e que interessam a este estudo), um saber de baixo (o Sul, a periferia, mas também a mulher - uma coletividade global redefinida, portanto, não a partir de uma identidade essencial, mas política, coletiva, menor). O outro tem saberes tão importantes quanto os dos críticos estadunidenses, diz ela, e ao se reservar a ele um lugar apenas de informante dentro de um saber definido a priori não há lugar para que venham à tona novas formas de saber. Onde tudo já está planificado, não há espaço para a imaginação e o impossível. Assim, para que um "comparativismo responsável possa ter algum uso possível no treinamento da imaginação, deve se aproximar diacronicamente dos sistemas éticos culturalmente diversificados, através da história dos impérios multiculturais, sem conclusões $a$ priori" (Spivak, 2009, p. 29), é dizer, se aproximar da "tarefa de tradução, não de uma língua a outra, mas do corpo à semiosis ética" (Spivak, 2009, p. 30). Para alcançar o que propõe a tarefa seria preciso pensar em termos de coletividades planetárias e não em termos de globalização. Não negar as coletividades quer dizer pensar além de um humanismo abstrato que nivela as culturas e as diferenças em nome de uma categoria ou valor com base no homem + branco + europeu e ainda permite sair daquela leitura que reduz a obra à nação onde foi gerada. Pensar as coletividades, para Spivak é pensar quem somos nós, quem ocupa o lugar do humano no humanismo. Pensar as coletividades é pensar o contrário do anseio de dar conta do todo:

Espero que a nova Literatura Comparada se aproxime das minorias mais antigas: as africanas, as asiáticas, as hispânicas. Que se proponha um itinerário pelo novo póscolonialismo das regiões pós-soviéticas e o lugar particular que o Islã ocupa no mundo fraturado de hoje. Não tudo para todos, nem de uma só vez. Mas sim um formato plausível de Literatura Comparada - histórico e linguístico - para cada amostra que se selecione de algum dos lugares, preenchendo o pano de fundo com as novas ferramentas de referência propostas pelo modelo de Franco Moretti (Spivak, 2009, p. 125).

A tarefa da imaginação, materializada na tarefa da tradução no sentido de aproximação em direção a outras éticas seria imaginar uma planetariedade com base nas culturas precapitalistas do planeta (Spivak, 2009, p. 148). Sair do modelo da globalização, sair da hegemonia da língua inglesa, sair do "nacionalismo americano disfarçado de globalização" (Spivak, 2009, p. 48). ${ }^{2}$

\footnotetext{
${ }^{2}$ A proposição de Spivak se aproxima, em alguma medida, do que propõe também Walter Mignolo, no sentido de sair da hegemonia europeia e estadunidense. Mignolo, porém, parte da discussão do lugar de enunciação, como reivindicava Achugar na passagem citada anteriormente, colocando em circulação o pensamento teórico e filosófico da América Latina, descrevendo um enorme "desenho no tapete", para retomar Henry James e Casanova, constituído por vozes inteiramente localizadas nesse continente (Mignolo, 2005).
} 


\section{Revisão de Brasil}

Haroldo de Campos, no texto "Ruptura dos gêneros na América Latina" - que faz parte de uma publicação da década de 1970, América Latina en su literatura, organizado por César Fernandez Moreno, com ensaios de Antonio Houaiss, José Guilherme Merquior, Haroldo de Campos e Antonio Candido ao lado de Lezama Lima, Severo Sarduy, Noé Jitrik, Fernando Alegria, Juan José Saer, Mário Benedetti entre outros de igual plana - pede para buscar a mesma medida de rigor no tratamento das literaturas latino-americanas e europeias, o que nos faria mais críticos e menos nacionalistas ou regionalistas:

O crítico latino-americano, sobretudo no atual momento de emergência de nossas literaturas para o cenário mundial, não pode ter duas almas, uma para considerar o legado europeu, outra para encarar o caso particular de sua literatura. Deve situar-se diante de ambos com uma mesma consciência e um mesmo rigor, e somente dessa atitude exemplarmente radical pode resultar o reexame da nossa historiografia literária, que nem por ser relativamente recente está livre dos clichês da sensibilidade, da repetição irrefletida e monótona de julgamentos preconcebidos, que não resistem a uma análise instrumentada (Campos, 2000, p. 287).

O que interessa em tal visão de uma literatura que começa a entrar no concerto da literatura mundial é o apagamento das fronteiras e mesmo das condições de produção de uma literatura dita periférica. No texto, Haroldo de Campos reivindica Sousândrade como instaurador da modernidade, competindo com Mallarmé. Parte da questão "Qual seria, dentro do problema de uma superação do cânone dos gêneros e da sua linguagem exclusiva, a situação da literatura latino-americana?" (Campos, 2000, p. 286). e a responde não simplesmente a partir de Rubén Darío, e a modernidade latino-americana, com seu "galicismo mental" - a introdução de tendências e sonoridades da língua francesa na língua espanhola -, mas ainda antes dele, que publicou Azul em 1888, com o episódio do Inferno de Wall Street, de Sousândrade, fazendo uma operação crítica à historiografia tradicional brasileira, que vê nos românticos a instituição de uma literatura verdadeiramente brasileira:

A nova perspectiva que nos oferecem a poesia e a crítica modernas, dentro daquele mesmo rigor programático que nos faz rejeitar como desvalioso o elenco de românticos "maiores" e "menores" proposto pela historiografia brasileira tradicional, permite-nos, em compensação, reconhecer a genialidade de um poeta que foi marginalizado por seus contemporâneos precisamente porque sua linguagem ultrapassava o limiar de compreensão de seu tempo (Campos, 2000, p. 287).

Desse modo, Haroldo de Campos iria encontrar um escritor brasileiro à altura da modernidade francesa e com ela sincronizada temporalmente:

Pois Sousândrade é contemporâneo síncrono de Baudelaire [...]. Como Ezra Pound depois, obsediado pela ideia de um "inferno financeiro", Sousândrade vislumbra as mazelas do capitalismo florescente, no seu próprio centro de operações, Wall Street, e as verbera causticamente. É então que, sob pressão de novos conteúdos, ele apela para novas soluções formais. Antes de Mallarmé, cujo "Coup de Dés" é de 1897; mais radicalmente do que Poe, cuja poesia, sob muitos aspectos é ainda convencional, ele se deixa inspirar pelo mosaico telegráfico dos jornais" (Campos, 2000, p. 288-289).

A partir da ideia de constelação - Haroldo foi um dos mais finos leitores de Benjamin no Brasil - e de paideuma, com Ezra Pound - Haroldo de Campos faz um recorte estilístico e de gênero literário para colocar na mesma lista os autores europeus e o brasileiro. Um lugar de igualdade que nada deve à condição de país subdesenvolvido, periférico, com condições sempre denunciadas de semi-indigiência cultural. Exatamente a leitura em que insistem Casanova e Moretti, mesmo que a partir de diferentes perspectivas.

Para Casanova, Mário de Andrade é o primeiro revolucionário brasileiro, com Macunaíma, seu anti-Camões. A ruptura com a diç̧ão, com a formalidade, da língua portuguesa e a reivindicação de uma língua brasileira, tornariam este livro o marco de um "nacionalismo crítico-reflexivo" ou "nacionalismo paradoxal" (Casanova, 2002, p. 351). 
Mas é tomando as palavras de Antonio Candido em "Literatura e subdesenvolvimento", texto publicado pela primeira vez no mesmo livro em que está o texto de Haroldo de Campos, que ela faz um paralelismo entre as condições que levaram Paris a ser o centro legitimador da literatura no século XIX e até pelo menos 1960 e as condições dos países latino-americanos:

Também é possível medir a contrario a ausência ou a fraqueza de capital literário nacional em países muito despojados dele. O crítico literário brasileiro Antonio Candido descreve assim o que chama a "fraqueza cultural" da América Latina, relacionando-a quase termo a termo com a ausência de todos os recursos específicos que acabamos de descrever: em primeiro lugar, a alta taxa de analfabetismo, que implica, escreve Candido, a "inexistência, a dispersão e a fraqueza dos públicos disponíveis para a literatura, devido ao pequeno número de leitores reais", em seguida a "falta de meios de comunicação e difusão (editoras, bibliotecas, revistas, jornais); a impossibilidade de especialização dos escritores em suas tarefas literárias, geralmente realizadas como tarefas marginais ou mesmo amadorísticas" (Casanova, 2002, p. 31).

O diagnóstico da condição em que se encontrava o escritor latino-americano nos diversos países da América Latina na década de 1970, no que se refere à vida cultural, não difere muito hoje, já que se o problema do analfabetismo foi quase totalmente solucionado, como previa Candido, a alfabetização não levou à leitura literária. Também os meios de comunicação e difusão, que se multiplicaram na atualização e mundialização perfeitamente acabada pela internet, não necessariamente ampliaram o público leitor e os interesses em literatura. A fraqueza cultural, no entanto, não é somente mais um problema latino-americano, necessariamente ligado à economia, mas a uma perda da centralidade da literatura, o que vem sendo estudado tanto em termos positivos como negativos e cuja discussão excede o tópico deste artigo.

O que interessa para a nossa discussão é o modo de pensar a literatura brasileira no contexto latino-americano de inserção no debate sobre a literatura-mundo. E nesse sentido, o texto de Candido nos interessa na medida em que coloca em cena todo um modo de pensar a nossa literatura a partir da ideia de "atraso" e "dependência", termos tomados de uma leitura profundamente informada pela análise econômica e sociológica cujo bastião é a consciência de país subdesenvolvido.

Para Candido, como é conhecido, "a incultura geral produzia e produz uma debilidade muito mais penetrante, que interfere em toda cultura e na própria qualidade das obras" (Candido, 1987, p. 148). O escritor brasileiro e latino-americano, "pela falta de pontos locais de referência", e por escrever "como se na Europa estivesse seu público", acaba degenerando em obras que "podiam não passar de exercícios de mera alienação cultural" tomadas como requintadas por assimilarem a "moda europeia" (Candido, 1987, p. 148). Nesse texto, Candido volta à afirmação da qual parte em Formação da literatura brasileira, de que nossa literatura, e agora, por extensão, toda a literatura latino e norte-americana é "galho das metropolitanas", consistindo aquilo que se chamou de autonomia uma mera transferência da dependência: da portuguesa ou espanhola para a francesa. A "influência inevitável, sociologicamente vinculada a nossa dependência", é o "vínculo placentário", "não uma opção, mas um fato quase natural" (Candido, 1987, p. 151):

Jamais criamos quadros originais de expressão, nem técnicas expressivas básicas, no sentido de que o são o Romantismo, no plano das tendências; o romance psicológico, no plano dos gêneros; o estilo indireto livre, no da escrita. E embora tenhamos conseguido resultados originais no plano da realização expressiva, reconhecemos implicitamente a dependência. Tanto assim que nunca se viu os diversos nativismos contestarem o uso das formas importadas, pois seria o mesmo que se oporem ao uso dos idiomas europeus que falamos. O que requeriam era a escolha de temas novos, de sentimentos diferentes (Candido, 1987, p. 151-152).

Num outro texto, "Literatura de dois gumes", do mesmo livro, Candido vai ler a consequência desse retorno em termos de temas novos e sentimentos diferentes, que "imprime na expressão herdada certas inflexões que a tornaram capaz de exprimir também a nova realidade natural e humana", chegando a modificar, portanto, a literatura já existente (Candido, 1987, p. 165). 
Apesar de nossa dependência, então, "influímos de volta nos europeus" com a "afinação dos instrumentos oferecidos". O "modo peculiar de nossos países serem originais" está dado no "processo de fecundação criadora da dependência" (Candido, 1987, p. 152) presente desde o Modernismo Latino-americano (que corresponde ao nosso Simbolismo). A passagem da dependência para a interdependência só se daria, no entanto, quando a influência se tornaria interna e não mais dos modelos estrangeiros imediatos. Tese conhecida de Candido para pensar Machado, que teria aprendido tanto com os acertos de Shakespeare quanto com os erros de Alencar. De modo semelhante:

Os criadores do nosso Modernismo derivam em grande parte das vanguardas europeias. Mas os poetas da geração seguinte, nos anos de 1930 e 1940, derivam imediatamente deles - como se dá com o que é fruto de influências em Carlos Drummond de Andrade ou Murilo Mendes. Estes, por sua vez, são inspiradores de João Cabral de Melo Neto, apesar do que este deve, também, primeiro a Valéry, depois aos espanhóis, seus contemporâneos (Candido, 1987, p. 153).

O que Candido defende, portanto, é o nascimento de uma tradição brasileira. Uma linha forte capaz de influenciar, de se tornar incontornável para os escritores posteriores, o "estágio fundamental na superação da dependência" (Candido, 1987, p. 153).

O passo seguinte para a interdependência seria tornar-se uma influência para a Europa. Parte (natural?) do processo de formação da literatura brasileira, que poderia ter sido iniciado com Machado de Assis, "cuja originalidade não é menor" que a de Borges verdadeiramente um instituidor de modernidade, como apontam Beatriz Sarlo e SanchesPrado, e "o primeiro caso de incontestável influência original [...] sobre os países fontes" no dizer de Antonio Candido - mas que se perdeu "na areia de uma língua desconhecida, num país então completamente sem importância" (Candido, 1987, p. 153).

Nem Machado, nem os "poetas de alto vôo" apontados por Candido na citação anterior exerceram influência fora de seu país; somos parte, portanto, de "uma cultura mais ampla, da qual participamos como variedade cultural" (Candido, 1987, p. 154). O nosso problema do atraso e da dependência, sempre reiterado por Candido, acaba fazendo nossa literatura oscilar entre a "imitação servil ou o exotismo" no polo negativo e a "assimilação recíproca", a "participação nos recursos que se tornaram bem comum" no polo positivo (Candido, 1987, p. 155).

Em "Apesar de dependente, universal" texto de Silviano Santiago de 1980, o autor parte de uma concordância com Candido em relação à perspectiva e à avaliação de que nossa literatura "comparada às grandes é pobre e fraca", mas pede ajuste de método, "cuidado com a estratégia de leitura", pois "tomando como base os princípios etnocêntricos - fonte e influência - da literatura comparada, apenas insistiremos no seu lado dependente, nos aspectos repetitivos e redundantes" (Santiago, 1982, p. 20). Contra, então, o "pensamento que se quer dependente" e que "não surge só como uma reflexão sobre dados empíricos de uma nação", mas que "é e sempre foi também uma ficção sob (e não sobre) a cultura ocupante" (Santiago, 1982, p. 21), apresenta três "antídotos fabricados desde o modernismo":

Primeiro. A noção mal-intencionada da antropofagia cultural brilhantemente inventada por Oswald de Andrade, num desejo de incorporar, criativamente, a sua produção dentro de um movimento universal. Segundo. A noção de "traição da memória", eruditamente formulada por Mário de Andrade através de suas pesquisas em música com vistas a uma produção nacional-popular [...]. Terceiro. A noção bem-pensante e possivelmente ideológica de "corte radical" em geral implicado (às vezes não explicado) pelos sucessivos movimentos de vanguarda, e recentemente defendido e daquela forma cognominado pelo grupo concretista paulista (Santiago, 1982, p. 21-22).

Os três antídotos não fariam desaparecer a dependência, nem fingiriam que ela não existe, mas subverteriam as noções de originalidade e atraso, fazendo cair a hierarquia pela subversão dos valores etnocêntricos. Os três momentos de universalização da literatura brasileira, de inserção mesma na discussão transnacional, talvez muito mais clara pela noção 
de "bucho de ruminante", ${ }^{3}$ tomada a Machado de Assis por Haroldo de Campos em "Da razão antropofágica: diálogo e diferença na cultura brasileira" (Campos, 2006), colocam em circulação uma ideia de mistura, pluralização deshierarquizada em que a ideia de atraso perde relevância. Ao reivindicar o Barroco como o momento de um intenso diálogo entre os escritores latino-americanos - "Um diálogo explícito: Sor Juana discutia as conquistas teológicas do Padre Vieira", ou implícito: "o baiano Gregório, a mexicana Sor Juana, o peruano Caviedas, todos eles participavam de um discurso que se revezava tropologicamente, ainda quando não houvesse contemporaneidade exata nem referência alusiva direta" (Campos, 2006, p. 242) - e a poesia concreta como representação do "momento de sincronia absoluta da literatura brasileira" que lança o nacional como diferença e que marca "o lugar operatório da nova síntese do código universal", Haroldo de Campos insiste na abertura de um novo processo no qual "autores de uma literatura supostamente periférica subitamente se apropriam do total do código, reivindicam-no como patrimônio seu, como um botim vacante à espera de um novo sujeito histórico (Campos, 2006, p. 246). Dessa maneira, ao apropriar-se do que é pensado como sendo o do outro, o do centro, o da cultura forte de igual para igual, "o caso brasileiro passava a ser a óptica diferenciadora e a condição de possibilidade. A diferença podia agora pensar-se como fundadora" (Campos, 2006, p. 242).

Não é outra a leitura que Silviano Santiago faz em "Eça de Queiroz, autor de Madame Bovary". Partindo da leitura também (des) e apropriadora de Borges em "Pierre Menard, autor de Quixote", Santiago mostra como Eça de Queiroz reescreve o romance de Flaubert imprimindo-lhe uma diferença radical: "A meditação sobre a obra anterior conduz o artista lúcido à transgressão do modelo" (Santiago, 1978, p. 64); "A obra segunda, porque comporta em geral a crítica da anterior, se impõe com a violência desmistificadora das planchas anatómicas que deixam a nu a arquitetura do corpo humano" (Santiago, 1978, p. 59).

Tanto Haroldo de Campos como Silviano Santiago foram duramente criticados por Roberto Schwarz em "Nacional por subtração", texto de 1986, publicado em 1987 em Que horas são? O ataque vai autorizado pela armadura do "fato" 4 contra a ficção, estratégia de que lança mão Schwarz logo no início do texto. É uma denúncia da "filosofia francesa", especialmente Foucault e Derrida, uma "crítica de corte filosófico abstrato" que seria "impotente", porque "nada diz sobre as realidades" a que o nacionalismo deve a força (Schwarz, 1987, p. 36). Para Schwarz, a ficção que essas teorias levam a cabo, e cita como exemplo os textos "O entre-lugar do discurso latino-americano" de Silviano Santiago e "Da razão antropofágica..." de Haroldo de Campos, não dariam conta de "equacionar ou combater relações de subordinação efetiva" (Schwarz, 1987, p. 36):

De atrasados passaríamos a adiantados, de desvio a paradigma, de inferiores a superiores (aquela mesma superioridade, aliás, que esta análise visa suprimir), isto porque os países que vivem na humilhação da cópia explícita e inevitável estão mais preparados do que a metrópole para abrir mão das ilusões da origem primeira (ainda que a lebre tenha sido levantada lá e não aqui). Sobretudo o problema da cultura reflexa deixaria de ser particularmente nosso, e, de certo ângulo, em lugar da almejada europeização ou americanização da América Latina, assistiríamos à latinoamericanização das culturas centrais (Schwarz, 1987, p. 36-37).

O tom de deboche não esconde certa reivindicação do nacional, ainda que o texto declaradamente invista contra o "nacionalismo patrioteiro", para recuperar uma expressão de Candido. A ideia mesma de antropofagia não passaria de uma aposta ingênua - "A distância no tempo torna visível a parte de ingenuidade e também ufanismo nestas propostas extraordinárias" (Schwarz, 1987, p. 38) - diante do "fato" de que entre as pessoas educadas "uma categoria social e não um elogio" - há "o sentimento de viverem entre ideias que são

\footnotetext{
3 “O grande e inclassificável Machado, deglutidor de Laurence Sterne e de incontáveis outros (é dele a metáfora da cabeça como um "bucho de ruminante", onde, como lembra Augusto Meyer num atilado estudo de fontes, 'todas as sugestões, depois de misturadas e trituradas, preparam-se para nova mastigação, complicado quimismo em que já não é possível distinguir o organismo assimilador de matérias assimiladas')" (Campos, 2006, p. 236-237).

${ }^{4}$ Uma bela leitura da implicação da argumentação pelo "fato" neste texto de Schwarz foi feita por Marcos Siscar em "O discurso da História na Teoria Literária brasileira” (Siscar, 2010, p. 197-210).
} 
copiadas do estrangeiro e não refletem a realidade local", tese do conhecido texto "As ideias fora do lugar". Então, "a destruição filosófica da noção de cópia tampouco faz desaparecer o problema" (Schwarz, 1987, p. 39), diz ele.

\section{Entre o nacionalismo e o cosmopolitismo}

Os dois modos de ler a literatura brasileira e latino-americana de que venho tratando neste artigo - uma vinculada fortemente às "condições de produção", ao contexto imediato e, em última instância, nacional e outra de inserção transnacional, corte estético constelador, desvinculação da ideia de atraso pela leitura diferencial e transgressora de valores como fonte e influência - ficam ainda mais claros a partir dos anos 2000 na polêmica em torno da disputa entre o Machado "nacional" e o Machado "cosmopolita" levadas a público por Roberto Schwarz e Abel Barros Baptista, ambas respostas ao artigo de Michael Wood, publicado na New York Review of Books, "Um mestre entre ruínas".

Wood parte da conhecida tese de Schwarz em Um mestre na periferia do capitalismo, traduzido e lançado nos EUA juntamente com Memórias Póstumas de Brás Cubas e Dom Casmurro, de que o romance de Machado (e por extensão sua obra toda) é uma muito bem formulada crítica à elite brasileira, tomando a forma inovadora de Machado como "a estilização de uma conduta própria à classe dominante" . Para esse modelo, diz Wood, o de Schwarz, como o de Lukács na Teoria do romance, "a literatura não apenas representa a história como conjunto de eventos singulares e cumulativos como também a habita e articula, falando a língua com que cada época dialoga consigo mesma" (Wood, 2006, p. 505). Daí Wood pergunta: "E se não formos cativados pela 'comédia ideológica brasileira' em cena? Será que a única alternativa consiste em cair presa dos encantos narrativos de Brás Cubas, tornando-nos cúmplices de classe à distância?" (Wood, 2006, p. 506). Desviando para a questão de por que, afinal, quem lê Machado em qualquer parte do mundo o considera um mestre e, ao mesmo tempo, ele não é lido por um amplo número de leitores como foi, por exemplo, sempre este exemplo, Borges, o autor conclui que "Machado é um mestre por conta de seu ambiente e de seus temas brasileiros, não apesar deles". Mas, diz ele, "ainda precisamos saber em que consistem a mestria e a modernidade de Machado, por que seus romances são mais do que os documentos históricos oblíquos e sofisticados que Schwarz identifica" (Wood, 2006, p. 507). A crítica deveria ser capaz de responder a questão colocada pelo próprio Machado no romance: por que, afinal, ele é tão engraçado quanto soturno? Ou seja, lê-lo fora da ideia de documento. "Eu diria", é o que diz Wood, "que Machado é nosso contemporâneo porque suas preocupações ressurgem em todo lugar, como formações de nuvens ou protestos políticos, e porque não temos certeza sobre quem ele é" . E também: “O jogo de aparência e desejo, o mundo de contingências difusas, tem domicílio no Brasil de Machado, mas também topamos com eles em outros lugares e provavelmente não vamos parar de encontrá-los" (Wood, 2006, p. 510).

Em "Leituras em competição", em resposta a Wood, Schwarz (2006, p. 61) intenta demonstrar "o prejuízo estético contido na opção de ignorar as particularidades locais formalizadas pelo autor". Schwarz parte de um recenseamento da oscilação da crítica em relação à Machado, nacional e internacionalmente, entre os pólos de "clássico nacional anódino" ou "pesquisador das constantes da alma humana, acima e fora da história" e "dramatizador malicioso da experiência brasileira" (Schwarz, 2006, p. 62-63).

Para dar conta do debate atual sobre Machado, Schwarz recupera a discussão sobre as lutas próprias ao campo literário descritas por Casanova, reforçando outra vez a localização de Machado num Brasil do atraso e da incultura, que repõe a todo momento aquela pergunta do crítico inglês em relação a Rubén Darío: “Como é possível que um filho de Metapa, cidade menor de um país marginalizado em uma região periférica, seja capaz de articular uma prática literária universal?" (Sánches-Prado, 2006, p. 7). Adiante diria que a “a explicação adquire relevância nacional" (Sánches-Prado, 2006, p. 65), como que reivindicando mais uma vez a apropriação de Machado como nosso em operação contra uma desapropriação em curso pelos críticos internacionais, os peritos obstinados na 
identificação e incorporação de obras-primas ao repertório de clássicos internacionais. $\mathrm{O}$ problema: "O artista entra para o cânone, mas não o seu país" (Sánches-Prado, 2006, p. 68).

Schwarz reitera a crítica evidente em "Nacional por subtração" desmerecendo certa crítica que desprezaria o contexto, fazendo todo seu texto girar na dupla ótica do local versus universal como moeda de troca do texto versus contexto:

Nesta perspectiva, uma obra de terras distantes, como a de Machado de Assis, na qual se possam estudar com proveito - suponhamos - os procedimentos retóricos do narrador, as ambiguidades em que se especializam os desconstrucionistas, a salada estilística do pós-modernismo etc., estará consagrada como universal e moderna. A natureza sumária desse selo de qualidade, que corta o afluxo das conotações históricas, ou seja, das energias do contexto, salta aos olhos (Schwarz, 2006, p. 66).

A recensão faz saltar à vista um problema aparentemente incontornável e que está informando toda a discussão sobre a literatura mundial: uma oposição entre o universal e o local, já muito discutida e que derivou em termos conciliadores como o glocal, por exemplo, mas que é colocado como uma disputa entre a crítica dita internacional e a nacional - as tais leituras em competição - tanto no texto de Schwarz como no livro de Beatriz Sarlo (2005), Borges: um escritor en las orillas, que Schwarz usa como epígrafe.

Assim, a consagração atual de Machado de Assis é sustentada por explicações opostas. Para uns, a sua arte soube recolher e desprovincianizar uma experiência histórica mais ou menos recalcada, até então ausente do mapa do espírito. A experimentação literária no caso arquitetaria soluções para as paralisias de uma ex-colônia em processo de formação nacional. A qualidade do resultado se deveria ao teor substantivo das dificuldades transpostas, que são de várias ordens, não só artísticas. Para outros, a singularidade e a força inovadora não se alimentam da vida extra-literária, muito menos de uma história nacional remota e atípica. Observam que não foi necessário conhecer ou lembrar o Brasil para reconhecer a qualidade superior de Machado, nem para apontar a sua afinidade com figuras centrais da literatura antiga e moderna, ou com as teorias em evidência no momento, ou, sobretudo, com o próprio espírito do tempo (Schwarz, 2006, p. 67).

Para inquirir a disputa, ainda que tomando parte de um dos lados, como está claro desde o resumo do artigo, Schwarz lê uma crônica de Machado: "O punhal de Martinha", em que se coloca em paralelo e se discute a relevância histórica de uma figura como Martinha, a desconhecida enredada na realidade local cotidiana mais chã contra a figura histórica de Lucrécia, para levar à conclusão de que "Machado dá figura artística às anomalias" da integração interna e da articulação externa da ex-colônia, agora uma quase-nação" (Schwarz, 2006, p. 78):

A referência de fundo é a formação da nacionalidade nas condições herdadas da colonização, inevitavelmente fora de esquadro, se o esquadro forem as auto-idealizações da Europa adiantada. Traduzindo os termos pelo seu desempenho, "local" é a falta de mediações, a descontinuidade entre o dia-a-dia semi-colonial e a norma do mundo contemporâneo; e "universal" é o consagrado e obrigatório, que se torna um despropósito ou uma brutalidade quando aplicado sem mais a mesma circunstância [...] O universal é falso, e o local participaria do universal se não estivesse isolado (Schwarz, 2006, p. 78).

Não há nada de novo na leitura de Schwarz, nada que não conhecêssemos desde de As ideias fora de lugar, em que pese ser outro o texto de Machado. O que salta à vista é a obstinação do crítico de que "atrás dos rótulos estéticos e lógicos há luta de classes, luta entre nações, desproporção entre acumulações culturais respectivas, além de luta crítica" (Schwarz, 2006, p. 78). Situação também denunciada por Casanova e, de outro modo, por Spivak. Situação nunca negada pela crítica dita internacionalista, que inclui os críticos brasileiros com intenção internacionalista. O que nos faria avançar, e que Sarlo alcança em sua leitura de Borges, é a opção pelas duas leituras, ou pelo menos a não interdição a uma leitura com propósito cosmopolita da obra de Machado.

Partindo da diferença dentro da língua, o crítico português Abel Barros Baptista, da Universidade Nova de Lisboa - um português lendo a literatura brasileira como literatura estrangeira, como parte dos estudos de literatura brasileira no exterior -, situa o debate nos seguintes termos: “Estamos sempre em algum lugar - em algum local. A imediata consequência 
a extrair seria que o universal não existe pela simples razão de que ninguém o pode habitar" (Baptista, 2009, p. 63). Por outro lado, há outra forma de dizer que o universal não existe, simplesmente porque "o local não existe" (Baptista, 2009, p. 64). E isso porque o interior (o local) em oposição ao exterior (o universal) se tornou impossível pela "dissolução da autonomia numa rede de instâncias por definição exteriores, fundações, agências governamentais, outras universidades, editoras, centros de pesquisa, numa rede tendencialmente tão diversificada no mapa como similar nos padrões e critérios de avaliação" (Baptista, 2009, p. 64).

Advogando, então, por uma perspectiva cosmopolita, que designa como aquela que preserva a relação com a literatura, sem subordiná-la a qualquer relação com o Brasil, Abel Barros Baptista vai ligar o propósito cosmopolita à abertura de um espaço de hospitalidade incondicional, com Derrida:

Não um espaço superior e restrito, para onde alguns poucos afortunados são cooptados, pela Unesco ou pelo sucesso comercial, formando alguma espécie de cânone supranacional ou literatura internacional; não um espaço homogêneo, universal, sem fronteiras nem conflitos, onde o espírito vagueia livre; não um espaço essencial de onde derivem ou se deduzam todos os espaços mais restritos e nada essenciais - mas o espaço que se abstém de limitar e impor condições à entrada e à estada do estrangeiro, aquele que não pode deixar de ser reconhecido e não pode deixar de se reconhecer como estrangeiro, e designadamente dele espera a responsabilidade de circunscrever ele próprio a sua incompreensão e ignorância (Baptista, 2009, p. 67).

O que está em jogo é uma concepção de literatura não subordinada à nação e ao fato, mas, antes, aberta ao propósito cosmopolita, à pressuposição de que qualquer um - o estrangeiro - a possa ler e encontrar seus limites. Não significará isso supor que com o propósito cosmopolita se negue ou se afirme a nacionalidade da literatura. Filiando-se à linhagem do próprio Machado em "Instinto de nacionalidade", o espírito cosmopolita reconhece o desejo de nacionalidade, delimita-o, identifica-o como uma das forças em ação no Brasil, porém não subordina a leitura da literatura ao reconhecimento da nacionalidade.

Interessante o modo como Abel Barros Baptista lê a tão inevitável tese das formas europeias importadas e ressignificadas com os temas periféricos: ele reconhece "a instabilidade e a transportabilidade das formas diante das modalidades de apropriação, de enraizamento, de particularização" (Baptista, 2009, p. 73). Não um país dono de uma forma, mas a transportabilidade e variação das formas, impossibilitadas de nacionalização. Há variação geográfica, como demonstra Moretti em A literatura vista de longe, porém a mudança do ponto de vista nacionalizador para o cosmopolita permite ver escritores que permitem que a literatura se erga acima das condições em que surge.

O crítico português descreve um dispositivo de equívocos presente no Brasil desde o romantismo e já denunciado por Machado, cujo sintoma é justamente a persistência da oposição entre local e universal, por sua vez decorrente do "obscurecimento da diferença entre a noção de literatura como projeção subordinada a um ideal cosmopolita de literatura e a noção de literatura como projeto subordinado a um ideal nacional de país construindo-se dotado de literatura própria" (Baptista, 2009, p. 75). A oposição local/universal funciona como um instrumento do projeto de circunscrição nacional de literatura em que o estrangeiro não pode figurar senão como um leitor limitado da literatura nacional. E, conclui Barros Baptista (2009, p. 85), "Não há lugar, nessa distinção [a do estrangeiro e do nacional], para o estrangeiro que se interessa por Machado mas não se interessa pelo Brasil" na defesa que Schwarz faz da leitura nacionalista de Machado em resposta ao ataque de Wood.

A ideia cosmopolita que defende Barros Baptista, então, vai além da oposição entre universal e local, desmontando a barreira preservativa contra o estrangeiro que faz Schwarz.

O propósito cosmopolita pressupõe o governo do texto como promessa de inteligibilidade e prazer que o texto dirige à inteligência e à paixão do estrangeiro. A questão do cômico sombrio, como a questão da epopeia para Herculano, são exemplos disso. De um modo ou de outro, há um século ou hoje, no Rio ou em Nova York, alguma força requer dos leitores a formulação da mesma pergunta, a que ecoa no espaço primordial da originalidade das Memórias póstumas: por que cômico, se sombrio, por que sombrio, se cômico? (Baptista, 2009, p. 86). 
Esta abertura para fora de uma explicação para o Brasil seria a abertura outra vez para uma potência desmistificadora em que não há nada a resguardar, a circunscrever, uma abertura que recoloca a questão sobre a participação do Brasil no debate sobre a literatura mundial. Uma leitura que não suspende o que se sabe sobre as lutas pela visibilidade, tão institucionalizadas, tão enraizadas no campo do poder econômico, mas também que não subordina a ideia mesma de literatura à representação da identidade, dos problemas da realidade brasileira, do debate nacional. ${ }^{5}$

\section{Referências}

ACHUGAR, Hugo (2006). Apuntes sobre la "literatura mundial", o acerca de la imposible universalidad de la "literatura universal". In: SÁNCHES-PRADO, Ignacio (Ed.). América Latina en la "literatura mundial". Pittsburgh: Instituto Internacional de Literatura Iberoamericana, p. 197-212.

BAPTISTA, Abel Barros (2009). Ideia de literatura brasileira com propósito cosmopolita. Revista Brasileira de Literatura Comparada, Niterói, v. 11, n. 15, p. 61-87.

CASANOVA, Pascale (2002). República mundial das letras. Tradução de Marina Appenzeller. São Paulo: Estação Liberdade.

CAMPOS, Haroldo (2000). Ruptura dos gêneros na América Latina. In: MORENO, César Fernandez. América Latina en su literatura. 17. ed. México: Siglo Veinteuno.

CAMPOS, Haroldo (2006). Metalinguagem e outras metas. São Paulo: Perspectiva.

CANDIDO, Antonio (1987). A educação pela noite e outros ensaios. São Paulo: Ática.

HEISE, Eloá (2007). Weltliteratur, um conceito transcultural. Revista Brasileira de Literatura Comparada, Niterói, v. 9, n. 11, p. 35-58.

MIGNOLO, Walter (2005). La idea de América Latina: la herida colonial y la opción decolonial. Tradução de Silvia Jawerbaun e Julieta Barba. Barcelona: Gedisa.

MORENO, César Fernández (2000). América Latina en su literatura. México: Siglo Veintiuno.

MORETTI, Franco (2000). Conjectures on world literature. New Left Review, London, n. 1, Jan./Feb.

MORETTI, Franco (2003). More conjectures. New Left Review, n. 20, Mar./ Apr..

MORETTI, Franco (2005). Graphs, maps, trees. Abstract models for literary history. London: Verso.

SÁNCHES-PRADO, Ignacio (Ed.) (2006). América Latina en la "literatura mundial". Pittsburgh: Instituto Internacional de Literatura Iberoamericana.

SANTIAGO, Silviano (1978). Uma literatura nos trópicos. São Paulo: Perspectiva.

SANTIAGO, Silviano (1982). Vale quanto pesa. Rio de Janeiro: Paz e Terra.

SARLO, Beatriz (2005). Borges: un escritor en las orillas. Espanha: Siglo Veinteuno.

SCHWARZ, Roberto (1987). Que horas são? São Paulo: Cia. das Letras.

SCHWARZ, Roberto (2006). Leituras em competição. Novos Estudos - Cebrap, São Paulo, n. 75, p. 61-79, jul.

SISCAR, Marcos (2010). Poesia e crise: ensaios sobre a "crise da poesia" como topos da modernidade. Campinas-SP: Editora da Unicamp.

SPIVAK, Gayatri (2009). Morte de una disciplina. Tradução de Irlanda Villegas. Santiago do Chile: Palinódia.

WOOD, Michael (2006). Um mestre entre ruínas. Teresa: Revista de Literatura Brasileira, São Paulo, n. 6-7, p. 504-510.

\footnotetext{
${ }^{5} \mathrm{O}$ cosmopolitismo tem raízes fundas na discussão sobre literatura brasileira, a começar por Silviano Santiago. Mas essa discussão será matéria para outro ensaio.
} 